\title{
Factors Influencing Care Behavior of Certified Care Assistants for Older Adults with Dementia
}

\author{
Kim, Ji-yeon ${ }^{1} \cdot$ Tak, Sunghee $\mathrm{H}^{2}$ \\ ${ }^{1}$ Seoul Metropolitan Center for Dementia · Graduate School, Seoul National University, Seoul \\ ${ }^{2}$ College of Nursing · The Research Institute of Nursing Science, Seoul National University, Seoul, Korea
}

\begin{abstract}
Purpose: Korea is one of the most rapidly aging countries, accompanied by an increasing number of older adults with dementia. Certified-care-assistants are the primary care workers for these older adults. This cross-sectional descriptive study compared the factors influencing care behaviors among Korean and non-Korean certified-care-assistants in Korea. Methods: Participants, 113 Korean certified-care-assistants and 71 non-Korean certified-care-assistants, completed a survey questionnaire. The questionnaire was designed to assess dementia knowledge, attitude and care behaviors toward older adults with dementia. To determine the differences in these two groups, t-test was used. A stepwise multiple regression was performed to identify factors related to care behavior. Results: Significant differences in dementia knowledge, attitude and care behavior toward older adults with dementia emerged between Korean and non-Korean certified-care-assistants. Factors influencing care behavior varied by group. Dementia knowledge and education level were the significant factors of care behaviors in Korean certified-care-assistants, whereas attitude toward older adults with dementia was the significant factor in non-Korean certified-care-assistants. Conclusion: Findings indicate that different factors influence the care behavior of two groups. These findings can be utilized to develop certified-care-assistants' training curriculum that needs to be tailored by nationality to improve the quality of care for older adults with dementia.
\end{abstract}

Key Words: Dementia, Long-term care, Health Personnel, Knowledge, Attitude

\section{INTRODUCTION}

South Korea is one of the most rapidly aging countries. In 2014, people over 65 years comprised 13.1\%(662 million) of the total population. This number is estimated to be $40.1 \%$ by 2060 [1], making South Korea the second fastest aging country in the world [2].

In 2015, older adults with dementia in Korea numbered 65 million with a prevalence rate of $9.8 \%$. Due to the trend of rapid increase in the elderly population, older adults with dementia are estimated to be 100 million (10.3 $\%$ ) by 2024 and 200 million (12.3\%) by 2041. The number of older adults with dementia is expected to double every 17 years [3].

In 2008, the Korean National Health Insurance Corporation implemented Long-Term-Care (LTC) insurance to decrease the burden on family members who care for elders at home [4]. LTC insurance is a social insurance policy, with the goal of providing support to older adults who cannot live independently, due to old age or geriatric disease. LTC includes assistance with the Activities of Daily Living (ADL) such as feeding, dressing and toileting, provided by family care givers, Certified Care Assistants (CCAs) or nurses, for an extended period of time [5].

When older adults are not able to live independently at home, they are often placed in LTC facilities. Older adults with dementia comprise up to $78.9 \%$ of total LTC-facility residents in Korea and 51.8\% in Germany [6,7]. Registered nurses, certified nursing assistants, and CCAs are the care workers who provide direct care in Korean LTC facilities. Caring, which is an essential concept of nursing, becomes apparent through their behavior in their interactions with

\footnotetext{
Corresponding author: Tak, Sunghee $\mathbf{H}$

College of Nursing, Seoul National University, 103 Daehak-ro, Jongno-gu, Seoul 03080, Korea.

Tel: +82-2-740-8823, Fax: +82-2-741-5244, E-mail: shtak@snu.ac.kr
}

Received: Jun 5, 2018 / Revised: Sep 12, 2018 / Accepted: Nov 14, 2018

This is an open access article distributed under the terms of the Creative Commons Attribution Non-Commercial License (http://creativecommons.org/licenses/ by-nc/3.0), which permits unrestricted non-commercial use, distribution, and reproduction in any medium, provided the original work is properly cited. 
older patients [8]. Providing quality care may contribute to improving physical health and to the cognitive function of LTC-facility residents [9].

The law requires LTC facilities to staff one CCA per 2.5 residents [10]. CCAs must stay with residents and provide direct assistance whenever needed. A previous study reported that CCAs spend 207 minutes in providing direct assistance, whereas RNs or CNAs spend only 30 minutes during a 24-hour period in LTC facilities [6]. CCAs comprise $76.3 \%$ of an LTC facility's employees and are the main care workers for older adults with dementia [11].

The care behaviors of the CCA involve providing support for both physical and household activities for older adults who are unable to perform ADLs [12]. No minimum education is required to be a candidate for the CCA qualifying examination which is administered by a mayor or governor. The only requirement is that candidates must complete 240 hours of curriculum at a private CCAprogram institute. The law, however, does not regulate the institute regarding program quality control. Although majority of the educational content includes the content of caring for older adults, instructors can be nurses, social workers, physical therapists or nutritionists with some clinical experience. The curriculum consists of only 160 hours of classroom time, 40 hours of clinical practice in a home-care setting and 40 hours of clinical practice in a LTC facility or hospital [10]. CCAs are not required to take any continuing education, although their scope of practice is similar to the CNAs in the United States [13]. Furthermore, the Korean CCA certificate is not limited to nationality, education or age and is open to immigrants who wish to acquire a CCA certification. This lack of oversight has raised concerns about the low quality of care that CCAs provide to older adults [14].

Currently, the director of each municipality supervises the issuance of the CCA certificates [10], which challenges stakeholders to obtain accurate statistics on CCAs. As the CCA curriculum is not standardized and not adequately monitored, it is difficult to expect CCAs to provide highquality care for the older adult. Previous studies indicated that CCAs need additional curriculum on knowledge and attitudes toward older adults with dementia $[15,16]$.

In particular, adequate knowledge and attitude are important for CCAs who provide care for older adults with dementia. Older adults with dementia often have cognitive and emotional disorders and, as symptoms worsen over time, they need complex care from others. Previous studies showed that CCA care behaviors correlate with knowledge of dementia and attitude toward older adults with dementia $[17,18]$. Knowledge of older adults affects the attitude and behavior towards them, ultimately determining the quality of care for older adults. As a result, a CCAs' knowledge of dementia is an important factor when providing care for these older adults [19].

In general, being a CCA is considered as difficult, demeaning and low paid job. The Korean CCA employment rate is $25 \%$ and gradually decreasing. A high turnover rate also factors in. Recently, the number of non-Korean CCAs has increased. This group is now estimated to be actively entering the long-term care labor market [20].

Currently, the exact number of non-Korean CCAs working in Korea is not known. However, it has been reported that non-Korean workers, with relatively simple technical capabilities, have a work productivity of $57.1 \%$ compared to Korean workers. In addition, non-Korean workers' ability to increase the value of product or service is only 45.4 $\%$ compared to that of Korean workers [21]. To date, there is no previous research that reports the care behaviors of non-Korean CCAs.

The purpose of this study was to examine and compare current levels of knowledge regarding dementia, attitude toward older adults with dementia, and care behavior by Korean and non-Korean CCAs. In addition, this study explored factors associated with care behaviors among Korean and non-Korean CCAs to improve the quality of care for older adults with dementia.

\section{METHODS}

\section{Participants and Data Collection}

A cross-sectional, descriptive study design was employed. The convenience sample consisted of CCAs with certificates and at least one month of experience caring for an older adult with dementia. Data was accrued using a survey questionnaire and took place between January 2 and March 25, 2017.

The required sample size was calculated using $G^{*}$ Power (version 3.1.). A priori power analysis by $\mathrm{F}$ test calculation with effect size of .15 , significance level of .05 , statistical power of .95, revealed that the sample size should be 129. Considering the possibility of missing data, a total of 210 participants enrolled during the study period. Twentysix were excluded due to incomplete questionnaires. The final analysis included data from 184 participants.

To become a participant of the study, CCAs had to possess a CCA certificate, which is obtained by passing an exam in Korean. In addition, non-Korean CCAs had to earn at least a score of 70 or higher in the Business-test of Profi- 
ciency in Korean (B-TOPIK) test, which is a test conducted by the Korean Institute for Curriculum and Evaluation or obtain a level $4 \sim 6$ on the general Korean proficiency test, standard-test of Proficiency in Korean (S-TOPIK) [20]. Passing the CCA certification exam verifies that participants are able to read and understand Korean, as well as the questionnaire. Participants were asked to call for assistance when they were not clear about the questionnaire. The researcher would then explain the meaning of the questions.

Since CCAs did not wish to identify themselves, especially those who were non-Korean, the participants' work setting was not included in the questionnaire. The questionnaires were dropped off at nursing homes, day care centers and home care centers to a designated person. A snowball technique was used to find CCAs who would participate in the study by taking referrals from CCAs who had already participated.

\section{Ethical Consideration}

Approval from the university's Institutional Review Board (IRB No. 1701/001-005) was obtained prior to data collection. Study participants provided a written consent. All consent forms were kept in a locked cabinet, complicit with regulations.

\section{Measurements}

CCAs' demographic information included age, gender, marital status, education level, religion, nationality, experience living with an older adult, care experience in months, duty hours per week, and number of assigned residents. Knowledge of dementia was measured using the Dementia Knowledge Scale, by Hwang and Jang [18]. This instrument consisted of 20 items; 10 items addressed the disease, 3 items addressed the treatment of dementia, and 7 items addressed the care behavior for older adults with dementia. Correct answers were graded as 1 with incorrect answers and "I do not know" graded as 0 . Higher scores indicated a higher knowledge of older adults with dementia. To obtain Cronbach's $\alpha$ of the original study, the corresponding author of the original study was contacted. The researcher, however, was not able to obtain the information. This instrument, which is widely used, was used in Yoon and Ryu's study [17] and also in Noh, Lim and Hur's study [22]. Cronbach's $\alpha$ was .77 and, in this study, it was .66.

Attitude toward older adults with dementia was measured using the Attitude Towards Dementia Patients Scale developed by Hwang and Jang [18]. A total of eight items were graded on a 5-point Likert-type scale (1=not at all, $5=$ all the time). Higher scores indicate a positive attitude toward older adults with dementia. Cronbach's $\alpha$ was .674 in the original study [16] and .712 in Kim, Kim and Sung's study [23] and .79 in this study.

Care behavior for older adults with dementia was measured on the Care Behavior for Older Adults with Dementia scale originated by Hwang and Jang [18]. In the original study, two geriatric nursing professors and one nursing professor verified the content validity of the scale [18]. This 23-item scale consisted of four domains (safety, health, communication and ADL) on a 5-point Likert-type scale ( $1=$ not at all, $5=$ all the time). Higher scores indicate better care behavior for older adults with dementia. Cronbach's $\alpha$ was .83 in the original study [18] and .87 in Yoon and Ryu's study [17] and .93 in this study.

\section{Data Analysis}

Data were analyzed using the SPSS statistical program version 22. Participants' characteristics were described using descriptive statistics such as mean and standard deviation. A t-test was conducted to determine differences in the level of dementia knowledge, attitude toward older adults with dementia, care behavior, and background variables by nationality. Finally, stepwise regression analysis was performed to identify factors associated with care behavior in each group. Multicollinearity for regression analysis was checked by reviewing values of the Variance Inflation Factor $(\mathrm{VIF})=1 /$ tolerance. Findings revealed no multicollinearity among the predictors in the model. A $p$-value of less than .05 was considered statistically significant.

\section{RESULTS}

The general characteristics and study variables of each group are shown in Table 1. Of the 184 participants who completed questionnaire, the mean age was 56.0 years, ranging from 29 to 75 years. More than half of the participants $(n=107,58.1 \%)$ had a high school education, 46 had a middle school education (25.0\%), 20 had a college education (3 4 years, 10.9\%) and 11 had an elementary school education (5.9\%). Most were women $(93.5 \%)$ and were married $(78.3 \%)$. Most CCAs identified with a religion ( $\mathrm{n}=129,70.1 \%)$. Of all participants, 149 CCAs had an experience living with an elder $(80.9 \%)$ and their mean work experience was 59.4 months, ranging from 1 to 241 months. Their mean duty hours per week were 65.84 hours, 
Table 1. Descriptive Characteristics of Korean vs. non-Korean CCAs

$(N=184)$

\begin{tabular}{|c|c|c|c|c|c|c|c|}
\hline \multirow{2}{*}{ Variables } & \multirow[t]{2}{*}{ Characteristics } & \multirow{2}{*}{ Categories } & \multirow{2}{*}{$\begin{array}{c}\begin{array}{c}\text { Total CCAs } \\
(\mathrm{n}=184)\end{array} \\
\frac{\mathrm{n}(\%) \text { or } \mathrm{M} \pm \mathrm{SD}}{}\end{array}$} & \multirow{2}{*}{$\begin{array}{c}\begin{array}{c}\text { Korean CCAs } \\
(n=113)\end{array} \\
\mathrm{n}(\%) \text { or } \mathrm{M} \pm \mathrm{SD}\end{array}$} & \multirow{2}{*}{$\begin{array}{c}\begin{array}{c}\text { Non-Korean CCAs } \\
(\mathrm{n}=71)\end{array} \\
\mathrm{n}(\%) \text { or } \mathrm{M} \pm \mathrm{SD} \\
\end{array}$} & \multirow[t]{2}{*}{$\mathrm{t}$} & \multirow[t]{2}{*}{$p$} \\
\hline & & & & & & & \\
\hline \multirow{11}{*}{$\begin{array}{l}\text { General } \\
\text { characteristics }\end{array}$} & Gender & Male & $12(6.5)$ & $5(4.4)$ & $7(9.9)$ & & \\
\hline & & Female & $172(93.5)$ & $108(95.6)$ & $64(90.1)$ & & \\
\hline & Age (year) & & $56.0 \pm 7.90$ & $56.90 \pm 6.07$ & $54.62 \pm 9.99$ & 17.05 & .058 \\
\hline & Religion & Yes & $129(70.1)$ & $90(79.6)$ & 39 (54.9) & & \\
\hline & & No & $55(29.9)$ & $23(20.4)$ & $32(45.1)$ & & \\
\hline & Marital status & Married & $144(78.3)$ & $90(79.6)$ & $54(76.1)$ & & \\
\hline & & Other & 40 (21.7) & $23(20.4)$ & $17(23.9)$ & & \\
\hline & Education & Elementary school & $11(6.0)$ & $3(2.7)$ & $8(11.3)$ & & \\
\hline & & Middle school & $46(25.0)$ & $28(24.8)$ & $18(25.4)$ & & \\
\hline & & High school & 107 (58.1) & $69(61.1)$ & $38(53.5)$ & & \\
\hline & & College & $20(10.9)$ & $13(11.5)$ & $7(9.9)$ & & \\
\hline \multirow[t]{8}{*}{ Study variables } & Lived with & Yes & $149(81.0)$ & $90(79.6)$ & $59(83.1)$ & & \\
\hline & the elders & No & $35(19.0)$ & $23(20.4)$ & $12(16.9)$ & & \\
\hline & \multicolumn{2}{|c|}{ Work experience (month) } & $59.4 \pm 43.09$ & $65.88 \pm 44.40$ & $49.10 \pm 39.00$ & 0.23 & .012 \\
\hline & \multicolumn{2}{|c|}{ Duty hours per week } & $65.84 \pm 46.73$ & $56.79 \pm 37.15$ & $81.01 \pm 55.55$ & 53.25 & .002 \\
\hline & \multicolumn{2}{|c|}{ Number of assignments } & $6.89 \pm 5.80$ & $8.79 \pm 6.09$ & $3.92 \pm 3.74$ & 12.99 & $<.001$ \\
\hline & \multicolumn{2}{|c|}{ Knowledge of dementia } & $12.96 \pm 2.21$ & $13.05 \pm 2.38$ & $12.11 \pm 2.83$ & 4.38 & .001 \\
\hline & \multicolumn{2}{|c|}{ Attitude to dementia } & $30.70 \pm 6.01$ & $29.24 \pm 6.27$ & $33.02 \pm 4.75$ & 6.89 & $<.001$ \\
\hline & \multicolumn{2}{|l|}{ Care behavior } & $100.09 \pm 11.79$ & $97.80 \pm 11.56$ & $103.73 \pm 11.29$ & 0.00 & .001 \\
\hline
\end{tabular}

ranging from 5 to 168 hours per week. The number of assignments per CCA varied from 1 to 25 older adults per shift with a mean of 6.89 older adults. Mean level of dementia knowledge was 12.96 of 20, attitude toward older adults with dementia was 30.70 of 40 and the care-behavior level was 100.09 of 115 .

Korean natives comprised 113 CCAs, whereas 71 were from China, Vietnam and other countries. The mean age was 56.90 and 54.62 years for the Korean and non-Korean CCAs, respectively. More than half of the Korean CCAs $(61.1 \%)$ and approximately half of the non-Korean CCAs (56.5\%) were high school graduates. In both groups most of the CCAs were women, (95.6\% and 90.1\%, respectively) and were married (79.6\% and $76.1 \%$, respectively) $79.6 \%$ of the Korean CCAs and only half (54.9\%) of the non-Korean CCAs identified with a religion. Most of the CCAs $(79.6 \%$ and $83.1 \%$, respectively) in both groups had an experience living with an elder. Their mean work experience was 65.88 and 49.10 months, respectively. Their mean duty hours per week were 56.79 hours for Korean CCAs and 81.01 hours for non-Korean CCAs. The mean number of patient assignments was 8.79 for Korean CCAs and 3.92 for non-Korean CCAs. Mean level of dementia knowledge was 13.05 and 12.11, respectively. Attitude towards older adults with dementia was 29.24 and 33.02, respectively, and the care-behavior level was 97.80 and 103.73, respectively in Korean and non-Korean CCAs.

The t-test revealed that significant differences emerged between Korean and non-Korean CCAs in religion, work experience, duty hours per week, number of assignments, level of dementia knowledge, level of attitude toward older adults with dementia, and level of care behavior. Results of multiple regression showed that, knowledge about dementia $(\beta=.59, p<.001)$ and education $(\beta=-19, p<.001)$ influenced caring behavior in Korean CCAs. Attitude towards older adults with dementia $(\beta=.43, p<.001)$ was found to have a positive influence on caring behaviors in non-Korean CCAs.

The results of the regression analysis hypothesis were all shown to be satisfied. First, the Durbin-Watson statistic was 1.95 and 2.09, which is close to the reference value of 2 , which means that there is no autocorrelation of the error. Next, as a result of the correlation between independent variables using the tolerance and VIF value, 
Table 2. Multiple Regression for Factors Affecting Care Behaviors for Older Adults with Dementia in Korean and Non-Korean CCAs

\begin{tabular}{|c|c|c|c|c|c|c|}
\hline Variables & Categories & B & $\mathrm{SE}$ & $\beta$ & $\mathrm{t}$ & $p$ \\
\hline \multirow[t]{2}{*}{ Korean CCAs } & (Constant) & 72.73 & 7.29 & & 9.97 & $<.001$ \\
\hline & Knowledge of dementia & 2.87 & 0.41 & .59 & 6.96 & $<.001$ \\
\hline
\end{tabular}

\section{Non-Korean CCAs}

\author{
(Constant) \\ Attitude to dementia
}

\begin{tabular}{|c|c|c|c|}
\hline 68.31 & 9.27 & & 7.36 \\
\hline 1.06 & 0.27 & .43 & 3.82 \\
\hline
\end{tabular}

Durbin-Watson=1.95, F=24.05, $p<.001$, Adj. $R^{2}=.32$

Durbin-Watson=2.09, F=14.60, $p<.001$, Adj. $\mathrm{R}^{2}=.17$

there was no violation of multicollinearity with a tolerance limit of 0.1 or more and a VIF value of 10 or less. To explain the factors associated with care behavior in two CCA groups, stepwise multiple regression for care behavior indicated that the model explained $17.5 \%(\mathrm{~F}=14.605$, $p<.001)$ and $32.0 \%(\mathrm{~F}=24.050, p<.001)$ of the variance in Korean and non-Korean CCAs, respectively. As shown in Table 2, significant factors related to care behavior were dementia knowledge and education level in Korean CCAs. Among non-Korean CCAs, attitude toward older adults with dementia was the only significant factor associated with care behavior.

\section{DISCUSSION}

This study focused on dementia knowledge, attitude toward older adults with dementia and care behavior among CCAs in Korea. In particular, the difference between Korean and non-Korean CCAs was compared and factors influencing care behavior for older adults with dementia was identified. Significant differences were found in work experience, duty hours per week and number of assignments between Korean and non-Korean CCAs. Korean CCAs had longer work experience and higher numbers of assignments per shift, whereas non-Korean CCAs had longer duty hours per week. In general, CCAs in nursing homes worked a three-shift schedule while CCAs in home-care settings and long-term care hospitals were needed 24 hours a day and assigned to only one or two older adults. This result suggests that Korean CCAs may tend to work in nursing home settings while non-Korean CCAs are likely to work in home-care settings and longterm care hospitals. A future study is needed in order to examine the work settings of CCAs and the effects of the work setting on their care behavior.

The study findings also showed a significant difference in the level of dementia knowledge, attitude and care be- havior toward older adults with dementia between the two groups. Korean CCAs had higher levels of dementia knowledge while non-Korean CCAs had higher levels of attitude and care behavior toward older adults with dementia. In Yun and Ryu's study [17] with CCAs working in nursing homes, their dementia knowledge was 15.2 out of 20, which was higher than the Korean CCAs and nonKorean CCAs in this study. This may be due to a mixture of work settings of the participants. That Korean CCAs had higher levels of knowledge than non-Korean CCAs may result from their longer experience and the greater volume of the number of patient assignments per shift. Korean CCAs may have experienced a greater variety of older adults with dementia and their various needs and symptoms. This result is consistent with a previous study that found higher levels of knowledge of dementia correlated with longer experience [24]. Higher levels of dementia knowledge can also be explained by higher education levels in Korean CCAs compared to non-Korean CCAs; yet, no significant difference was found in the education level between the groups. Even though the non-Koreans' language skill has been tested through the Korean language proficiency test, language barriers in non-Korean CCAs may have led to lower levels of dementia knowledge. The linguistic competency test is given to foreign nurses working in the U.S., too; however, it has shown that they still experience language barriers in reporting, due to the difficulty of understanding the language or accent [25].

In Hwang and Jang's study [18], the level of attitude towards older adults with dementia was 30.70 out of 40 which was similar to that of the average Korean and nonKorean CCAs (30.2) in this study. When comparing the two groups, the Korean CCAs' attitude measured lower than the non-Korean CCAs (29.24 vs. 33.02, respectively). For the care behavior for older adults with dementia, previous studies $[17,22]$ showed a score of $92.86 \sim 86.82$ out of 
115. In this study, Korean CCAs had a slightly higher score of 97.80 while non-Korean CCAs showed a much higher score of 103.73. In addition, non-Korean CCAs had higher levels of attitude and care behavior toward older adults with dementia, longer duty hours per week, and fewer number of assignments per shift, compared to Korean CCAs. A previous study of Chinese-Korean uncertified care assistants showed that they felt rewarded by caring for patients. They reported that their job satisfaction was also higher than the Korean uncertified care assistants [23]. This result may be due to a participant's work setting in which non-Korean CCAs are assigned to a smaller number of older adults. They may be able to spend more time and provide personalized care for each older adult. In previous studies in nursing homes [17], having fewer older adults assigned may lead to increased care behavior. However, there are inconsistent findings in regard to longer duty hours per week and higher levels of attitude.

Home care may be quite different from working in a hospital or nursing home. Duty hours per week, number of assignments per shift and number of staff working together can differ. In long-term care hospitals and nursing homes, CCAs tend to work under the supervision of RNs and CNAs. Thus, CCAs are not the only staff providing care for older adults. However, in a home care situation, CCAs are the only ones providing care to older adults (the setting where non-Korean CCAs usually work). They must work independently, which may result in higher levels of attitude toward older adults compared to Korean CCAs.

Stepwise multiple regression analysis indicated that the factors influencing care behaviors differed in the two groups. Study findings confirmed that factors positively influencing the care behaviors by Korean CCAs were dementia knowledge and education level. Attitude toward older adults with dementia was the factor influencing positive care behavior for older adults with dementia for non-Korean CCAs. No study has previously been done with CCAs from other countries working in Korea. Previous studies with Korean CCAs indicated that the influencing factors for care behavior of CCAs included the attitude toward dementia and the level of education [26], the experience of in-hospital education, and the positive attitude toward patients [22].

This finding confirms the importance of dementia knowledge and attitude when caring for older adults with dementia. According to the KAP (Knowledge, Attitude, and Practice) study that was introduced in the learning theory, knowledge should be preceded by a positive attitude toward positive behavior [27]. Evidence shows that de- mentia knowledge and attitude toward older adults with dementia influence care competency among CCAs [28].

The study findings indicate that the training curriculum needs to be tailored to Korean CCAs and non-Korean CCAs. Korean CCAs need to focus on their attitude toward older adults with dementia and non-Korean CCAs need more dementia-knowledge education, considering their language barrier. Furthermore, required knowledge and skills can vary depending on their work setting. In addition to initial training, supplemental training and continuing education are critical for CCAs.

In this study, work setting was not included in the questionnaire due to CCAs' unwillingness to disclose their personal information. The majority of Korean CCAs were directly contacted at nursing homes, and the rest were recruited by referrals using a snowball technique. However, because non-Korean CCAs were hard to reach, less than ten were recruited from nursing homes, and most of the non-Korean CCAs were reached by referrals and snowball technique. By looking at this recruitment process, it is speculated that the nationality of CCAs may be significantly associated with the setting or condition in which they work. Korean CCAs may tend to work in nursing homes, and non-Korean CCAs tend to work in various settings, such as home care and long-term care hospitals where they provide 24-hour care by the patient's bedside. Further studies are needed in order to improve the recruitment strategies of non-Korean CCAs who are reluctant to participate in research, assess their work setting and condition, and examine their effects on care behavior for older adults with dementia.

The data were provided through convenience sampling, which limits the generalization of the results. Also, instruments used to assess knowledge, attitude, and care behaviors are specific to older adults with dementia and are not applicable to residents with other diagnoses. However, the majority of LTC-facility residents are diagnosed with dementia, so this study provides useful findings to improve the quality of care. For the Dementia Knowledge Scale, the Cronbach's $\alpha$ was .66, which is considered a little low. However, this instrument has been widely used, and it has been proven to show high Cronbach's $\alpha$ in other studies.

\section{CONCLUSION}

Study results indicate dementia knowledge and attitude affect the care behaviors of CCAs for older adults with dementia. Findings also indicated that CCAs with different nationalities may have different needs for addi- 
tional education and training. Future investigation is required to examine the effects of a tailored educational training program for CCAs to increase knowledge, attitude, and care behavior for older adults with dementia. Improving CCAs' competency of caring is critical to providing high quality care that older adults with dementia deserve.

\section{REFERENCES}

1. Statistics Korea. Korea and International Demographics Prospect [Internet]. Daejeon: Statistics Korea; 2015 Jun 8 [updated 2015 Jun 8; cited 2016 Oct 17]. Available from: https://kostat.go.kr/portal/korea/kor_nw/2/1/index.boar $\mathrm{d}$ ?bmode $=$ read \&bSeq $=\& a S e q=347102 \&$ pageNo $=1 \&$ row $\mathrm{Nu}$ $\mathrm{m}=10 \&$ navCount $=10 \&$ currPg $=\&$ sTarget $=$ title\&sTxt $==\% E C$ $\% 84 \%$ B8\%EA $\%$ B3\%84

2. United Nations. World population prospects: the 2015 revision [Internet]. New York: United Nations, Department of Economic and Social Affairs, Population Division; 2015 Jul 29 [updated 2015 Jul 29; cited 2016 Oct 3]. Available from: https://esa.un.org/unpd/wpp/publications/files/key_find ings_wpp_2015.pdf

3. National Institute of Dementia. Korean dementia observatory [Internet]. Seoul: National Institute of Dementia; 2017 Feb 9 [updated 2017 Feb 9; cited 2017 Mar 8]. Available from: https://www.nid.or.kr/info/dataroom_view.aspx?bid=160

4. Korean National Health Insurance Corporation. Long term care insurance [Internet]. Wonju: Korean National Health Insurance Corporation; [cited 2018 Jun 15]. Available from: http://www.longtermcare.or.kr/npbs/e/b/101/npeb101m01 .web?menuId=npe0000000030

5. Colombo F, Llena-Nozal A, Mercier J, Tjadens F. Help wanted? providing and paying for long-term care. OECD Health Policy Studies. Paris, France: Organisation for Economic Cooperation and Development; 2011 May.

6. Lee M, Kim E. Relationship between resource utilization and long-term care classification level for residents in nursing homes. Journal of Korean Academy Nursing. 2010;40(6):903-12. https://doi.org/10.4040/jkan.2010.40.6.903

7. Hoffman F, Kaduszkiewicz H, Glaeske G, Bussche HVD, Koller D. Prevalence of dementia of in nursing home and community-dwelling older adults in Germany. Aging Clinical and Experimental Research. 2014;26(5):555-9. https://doi.org/10.1007/s40520-014-0210-6

8. Jonasson L, Liss P, Westerlind B, Bertero C. Corroborating indicates nurses' ethical values in a geriatric ward. International Journal of Qualitative Studies of Health and Well-being. 2011;6 (3):1-10.

9. Lee H, Lee H, Lee J. Predictors of facility adaptation in nursing home residents. Journal of Korean Academy of Nursing. 2009; 39(2):177-85.

10. Korean Ministry of Health and Welfare. Welfare of older persons act enforcement ordinance [Internet]. Sejong: Korean Ministry of Health and Welfare; 2018 Apr 25 [updated 2018 Apr 25; cited 2018 Jun 15]. Available from:

http://www.law.go.kr/lsSc.do?tabMenuId=tab18\&p1=\&sub Menu=1\&nwYn=1\&section=\&tabNo=\&query $=\% \mathrm{~EB} \% 85 \% \mathrm{~B} 8$ \%EC\%9D\%B8\%EB\%B3\%B5\%EC\%A7\%80\%EB\%B2\%95\#und efined

11. Korean National Health Insurance Corporation. Long term care insurance statistical yearbook [Internet]. Wonju: Korean National Health Insurance Corporation; 2017 Jul 18 [updated 2017 Jul 18; cited 2018 Jun 15]. Available from:

http://www.mohw.go.kr/react/al/sal0301vw.jsp?PAR_ME NU_ID=04\&MENU_ID=0403\&CONT_SEQ=340642\&page=1

12. Korean Ministry of Government Legislation. Welfare of Older Persons Act [Internet]. Sejong: Korean Ministry of Government Legislation; 2018 Mar 13 [updated 2018 Mar 13; cited 2018 Jun 15]. Available from:

http://www.law.go.kr/lsSc.do?tabMenuId=tab18\&p1=\&sub Menu=1\&nwYn=1\&section=\&tabNo=\&query=\%EB $\% 85 \%$ B8 \%EC\%9D\%B8\%EB\%B3\%B5\%EC\%A7\%80\%EB\%B2\%95\#und efined

13. You S. Comparisons of the nursing workforce with Japan, and the US. Journal of Digital Convergence. 2013;11(6):275-87.

14. Um G. Strategic proposal for the improvement of service quality of long-term care insurance in Korea. Health-welfare Policy Forum. 2008;142(8):38-46.

15. Cho N, Ko S, Kim C, Yang S, Oh K, Lee S, et al. The level of importance on education of long term care nursing assistants perceived by caregivers of the elderly. Journal of Korean Academic Society of Nursing Education. 2008;14(1):127-37. https://doi.org/10.5977/jkasne.2008.14.1.127

16. Cui Y, Fan R, Wang YM, Kaye AJ, Kaye AD, Bueno FR, et al. A changing healthcare system model: The effectiveness of knowledge, attitude, and skill of nursing assistants who attend senile dementia patients in nursing homes in Xi'an, China: a questionnaire survey. The Ochsner Journal. 2014;14: 328-34.

17. Yun S, Ryu S. Impact of dementia knowledge, burden from behavioral psychological symptoms of dementia and empathy in the caring behavior of certified caregivers in nursing homes. Journal of Korean Gerontological Nursing. 2015;17(3):131-41. https://doi.org/10.17079/jkgn.2015.17.3.131

18. Hwang S, Jang G. A study on the levels of dementia-related knowledge, attitude, and practice among nursing assistants caring for institutionalized elders with dementia. Journal of Korean Academy of Adult Nursing. 1999;11(3):378-88.

19. Hui J, Weiqin Y, Yan G. Family-paid caregivers in hospital 
care in China. Journal of Nursing Management. 2013;21(8): 1026-33. https://doi.org/10.1111/jonm.12017

20. Won S. Certified caregiver institution survey report [Internet]. Seoul: National Assembly Research Service, Social and Cultural Research, Health and Welfare Women's Division; 2009 Dec 16 [updated 2009 Dec 16; cited 2018 Aug 1]. Available from:

http://www.nars.go.kr/brdView.do;jsessionid=ELVUha81O FTRm93wJi1NsvY8wlvGRrymLvfgcVYGIZzijydOQvbGYx4 2EAMMtGJ1.EXTWASSVR01_servlet_engine1?currtPg=4\& $\mathrm{cmsCd}=\mathrm{CM} 0020 \&$ pnum $=0 \&$ cnum $=0 \& \mathrm{src}=\& \operatorname{srcTem} p=\&$ page Size $=10 \& b r d \_S e q=2157$

21. Jeon S. Analysis of production and value added effect of foreign worker inflow. Contemporary Society and Multiculture. 2013;3 (1):1-37.

22. Noh J, Lim E, Hur J. The factors influencing careworker's care performance for elders with dementia. The Korean Journal of Health Service Management. 2012;6(3):75-84. https://doi.org/10.12811/kshsm.2012.6.3.075

23. Kim G, Kim G, Sung M. Dementia-related knowledge and attitude among care workers - focusing on the care workers who got an education on dementia in Seoul Dementia Center. Korean Journal of Care Management. 2011;6:23-51.

24. Symth W, Fielding E, Beattie E, Gardner A, Moyle W, Franklin S, et al. A survey-based study of knowledge of Alzheimer's disease among health care staff. BMC Geriatrics. 2013;13(2):1-8. https:// doi.org/10.1186/1471-2318-13-2

25. Wagner L, Brush B, Castle N, Eaton M, Capezuti E. Examining differences in nurses language, accent, and comprehensibility in nursing home settings based on birth origin and country of education. Geriatric Nursing. 2015;35:47-51.

https://doi.org/10.1016/j.gerinurse.2014.10.012

26. Hong S, Kim G. A study of the acculturation meaning among Chinese-Chosun residential care attendants in long-term care setting. Journal of the Korean Geriatrics Society. 2010;30(4): 1263-80.

27. Kaliyaperumal K. Guideline for conducting a knowledge, attitude and practice (KAP) study. AECS illumination. 2004;4(1): 7-9.

28. Kim C. Influencing factors of the perceived formal caregivers' caring competences for elders with dementia. Journal of Korean Gerontological Nursing. 2013;15(2):95-102. 